\title{
Diagnosis of childhood asthma
}

\section{Levin MBChB, FCPaed, DipAllerg, MMed, PhD \& E Weinberg MBChB, FCPaed}

To cite this article: M Levin MBChB, FCPaed, DipAllerg, MMed, PhD \& E Weinberg MBChB, FCPaed (2011) Diagnosis of childhood asthma, South African Family Practice, 53:5, 437-439, DOI: $10.1080 / 20786204.2011 .10874129$

To link to this article: http://dx.doi.org/10.1080/20786204.2011.10874129
a (c) 2011 SAAFP. Published by Medpharm.

曲 Published online: 15 Aug 2014.

Submit your article to this journal $\pi$

Џll Article views: 93

Q

View related articles $\sqsubset$ 


\title{
Diagnosis of childhood asthma
}

\begin{abstract}
Levin M, MBChB, FCPaed, DipAllerg, MMed, PhD Paediatric Consultant at Red Cross Children's Hospital and Head of Division of Allergy, Department of Paediatrics and Child Health, UCT Weinberg E, MBChB, FCPaed, Paediatric Consultant at the Allergy Diagnostic and Clinical Research Unit, UCT Lung Institute Correspondence to: Dr Mike Levin, e-mail: michael.levin@uct.ac.za Keywords: childhood asthma, wheezing, coughing, chest tightness, shortness of breath, eczema
\end{abstract}

\section{Introduction}

Childhood asthma is characterised by episodes of wheezing and coughing, particularly at night. The cough is typically non-productive of sputum and is irritating and persistent. It is most troublesome in the early hours of the morning, especially between 1-2 am. Chronic cough may be a presenting symptom in young children. Wheezing, chest tightness, and shortness of breath become more obvious in children older than three years.

Acute exacerbations of asthma are frequently associated with viral upper respiratory tract infections, but may also be triggered by exercise, particularly in cold and dry weather, laughter, crying, and exposure to allergens and irritants such as petrol or paint fumes. There may be a seasonal variation in symptoms, and it is common to find a diurnal variation with waking in the early hours of the morning, and increased symptoms on getting out of bed.

In taking a history, it is important to enquire about symptoms being caused by exposure to allergens such as house dust and pets, and by physical factors such as cold air, mist, humidity or cigarette smoke. House dust mite is the most common allergen in children, particularly in the coastal regions. Bedding, carpets, and soft toys are the most common sources of mite exposure. Children spend a large part of the day in their bedrooms, so if patients are house dust mite sensitive, it is important to concentrate on keeping this area as dust-free as possible.

In schoolchildren, exposure to allergens in the classroom is important. House dust mite, cat, dog, and even horse allergens are brought into the classroom on the clothing of class mates, and sensitise asthmatic children.

The clinical history must always include questions on associated allergic conditions such as eczema and allergic rhinitis, and a family history of allergies, as asthma commonly occurs in families. Enquire about the birth and early post- natal history, as this may provide clues to predisposing factors related to transient wheezing of infancy or asthma. The parents' occupations and smoking habits may also have an impact on the child's illness.

\section{Examination}

The features of allergic disease are often present, and most such children have a rather pale facial appearance, particularly in those with associated allergic rhinitis. The lower eyelids are often puffy and have a blue discolouration ("allergic shiners"). The child often breathes through his or her mouth, and there may be a transverse nasal crease because of constant upward nose rubbing ("allergic salute") if allergic rhinitis is present.

Atopic eczema, which typically affects the flexures of the arms and legs, occurs in at least $50 \%$ of asthmatic children.

Children have a compliant thoracic cage and may develop a chest deformity with persistent asthma, especially pectus carinatum (pigeon chest) and a Harrison's sulcus. Those with severe asthma may be growth retarded and are often underweight.

Puberty may be markedly delayed in children with poorly managed or severe asthma, although most children eventually achieve normal adult height. It is important to measure the height and weight of these children regularly, and to plot these on growth charts.

If wheezing is present on chest auscultation, the response to a $\beta_{2}$ agonist bronchodilator should be determined. Disappearance of the wheeze is indicative of asthma. If wheezing is not detected, the response to a bronchodilator is measured by using a peak flow meter in children older than five years. 


\section{Differential diagnosis: infant wheezing}

Wheezing in infancy is common, but does not always mean that the infant has asthma. Allergy is the most important factor in predicting the persistence and severity of wheezing in children. Isolated wheezing episodes in infancy are unlikely to be associated with continuing asthma at the age of five years. Only $15-20 \%$ of infant wheezers continue to have asthma in later childhood.

There are two main categories of infant wheezers.

\section{Episodic viral wheezers}

Most wheezing infants have transient episodes of wheeze associated with viral infections. Affected children are symptomfree between episodes. Wheezing episodes usually disappear by the age of three to four years. Predisposing factors include maternal smoking during pregnancy, low birthweight, and lung problems associated with prematurity.

\section{Multiple-trigger wheezers}

Multiple-trigger wheezers are often infants in whom other manifestations of atopy or allergy, such as eczema or allergic rhinitis, are present. Affected children show symptoms between episodes, triggered not only by viruses, but also by other precipitants such as allergens, exercise, or cigarette smoke.This form of wheezing is far more likely to be true asthma, to persist, and to require long-term therapy.

The old maxim remains true and must always be borne in mind: "Not all that wheezes is asthma". Sometimes other causes of wheezing need to be excluded, such as an inhaled foreign body, enlarged mediastinal lymph nodes (especially tuberculous), anomalies of the airways, cystic fibrosis, ascaris infestation, and many others.

\section{Investigations}

Simple pulmonary function tests are used to determine the severity of airflow obstruction in children with asthma. These tests are used to confirm the diagnosis, in conjunction with the response to a bronchodilator, and to establish a baseline for therapy. Important tests include peak expiratory flow rate (PEFR) and forced expiratory volume in one second (FEV1).
A peak flow meter is used to measure the PEFR. It is a simple and easy-to-use instrument which gives reproducible readings. A Mini-Wright Peak Flow Meter, or similar, is most commonly recommended. The PEFR measures large airways obstruction, whereas the FEV1 gives information on both small and large airways.

Normal values for PEFR in children are given in Figure 1. A spirometer is needed to measure the FEV1. Most children from five years of age can perform the tests for PEFR and FEV1, but both of these are unsuitable for younger children.

\section{Bronchodilator test}

The PEFR is measured before and after a $\beta_{2}$ agonist bronchodilator is inhaled. An increase in flow rate of $15 \%$ or more post-bronchodilator, compared to the prebronchodilator value, confirms the diagnosis of asthma. $A$ modified bronchodilator response test may be performed in young children unable to perform spirometry or a peak flow rate. In such patients, response to a bronchodilator is measured by reduction in wheeze or respiratory rate or improvement in air entry. Some children with virus-induced wheeze may also respond, so the test forms part of an assessment for asthma and not the sole criterion. 
Table I: Classification of asthma based on asthma severity at presentation

\begin{tabular}{l|c|c|c}
\hline Intermittent & \multicolumn{2}{c}{ Persistent } \\
\cline { 3 - 4 } & & Mild & Moderate \\
\hline Daytime symptoms & $<2 /$ week & $2-4 /$ week & $>4 /$ week \\
\hline Night-time symptoms & $<1 /$ month & $2-4 /$ month & $>4 /$ month \\
\hline Peak expiratory flow rate (predicted) & $>80 \%$ & $>80$ & $60-80 \%$
\end{tabular}

\section{Classification}

Asthma severity is assessed at the first consultation, as initial treatment is dependent on this grading. Subsequent management relies on assessment of asthma control to guide decisions to either maintain or adjust therapy, i.e. to step it up if necessary, or step it down if possible.

The assessment of severity is used as a starting point to assign a child to a particular treatment group. It is performed between acute episodes in a patient who is not receiving long-term therapy. Assessment of severity depends on the frequency of symptoms and the obtained peak flow reading (the latter in children five years and older). Symptoms are divided into day- and night-time symptoms (essentially cough and wheeze). A patient must be assigned to the most severe grade in which any feature occurs.

It is important to establish whether symptoms are intermittent or persistent, because persistent asthma requires regular controller therapy. Persistent asthma is further subdivided into mild, moderate or severe (Table I). About $70 \%$ of childhood asthmatics will fall into the mildpersistent category, $25 \%$ into the moderate-persistent group, and $5 \%$ into the severe-persistent category.

\section{Treatment}

Optimal treatment of asthma requires an understanding of the central concept of asthma control, and how this is used to modify treatment. Environmental control and intermittent reliever therapy is all that is necessary for intermittent asthma. Persistent asthma requires regular antiinflammatory controller therapy. Inadequate adherence and poor technique are more usual causes for treatment failure than incorrect drug selection. Patient adherence must be assessed, and technique of drug administration witnessed at every visit.

The National Asthma Education Programme (www.asthma. co.za) provides free patient and doctor educational materials, and runs an asthma certificate course to teach doctors and nurses how to assess asthma and educate patients about how to use their medication to achieve optimum asthma control.

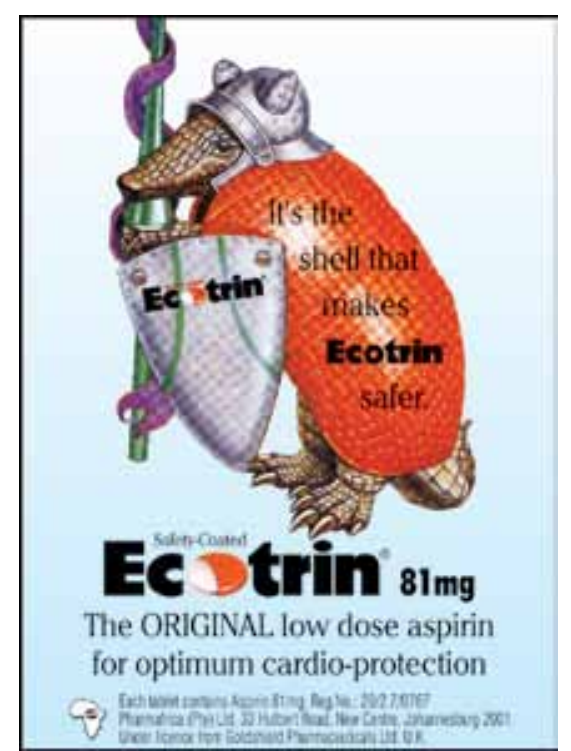

